\title{
Prevalence of COVID-19 in Al Qassim Province, Saudi Arabia: A Sociodemographic Analysis
}

\author{
Wafa Ali, Amal Alqufly, Ibrahim Aljabr, and Sharafaldeen Bin Nafisah
}

\begin{abstract}
BACKGROUND The resurgence of COVID-19 cases in Saudi Arabia, despite ongoing control measures, warrants further analysis.

AIM We aimed to investigate the prevalence and sociodemographic risk factors of COVID-19 in Al Qassim Province, Saudi Arabia. We explored perceptions toward vaccination, social isolation and community adherence to social distancing measures.

METHODS We collected data reported by the Weqaya, Saudi Centre for Disease Prevention and Control, and conducted a cross-sectional study within the province.

RESULTS Up to 9 May 2021, 15497 positive cases were detected, comprising a prevalence of $1.46 \%$. Uyun Al-Jiwa and Riyadh Al-Khabra had the highest infection rate. Our sample of 511 participants revealed an exposure rate of $52.1 \%(n=266)$ with no specific sociodemographic risk factor. Self-isolation following exposure to a confirmed or probable case occurred less among older age groups and married participants, and was not influenced by the presence of underlying chronic diseases. The majority of participants perceived community compliance with social distancing measures to fall within the 'sometimes' category. Finally, the vaccination acceptance rate was $72.6 \%(n=371)$.

CONCLUSION The findings of the current study emphasise the need to adopt further measures to encourage adherence to social distancing and self-isolation, especially among vulnerable groups.
\end{abstract}

Index Terms-Al Qassim COVID-19, sociodemographic risk factors, COVID-19 in Saudi provinces

\section{INTRODUCTION}

Up to now, seven coronaviruses are known to infect humans; the first four were identified in the mid-1960s. SARS$\mathrm{CoV}$ and MERS-CoV represent the fifth and sixth strains, which emerged in 2002 and 2012 respectively. Both caused severe symptoms and, within a short period, resulted in a pandemic [1]. The World Health Organisation (WHO) received reports of SARS-CoV from 29 countries, with 8096 peopleinfected between November 2002 and July 2003 and a mortality rate of $9.6 \%$ [2]. The MERS-CoV outbreak, on the other hand, infected 2494 people in 27 countries between April 2012 and November 2019, with a mortality rate of $34.4 \%$. Saudi Arabia suffered the most significant outbreak, with 2120 cases and 780 related deaths - a mortality rate of $37.1 \%$ [3].

In December 2019, several pneumonia patients were found to be carrying a novel coronavirus attributed to Wuhan, China. The rapid and continuous global spread of COVID-19 led the WHO to declare the outbreak a pandemic on 11 March

Wafa Ali, Amal Alqufly, Sharafaldeen Bin Nafisah are with Emergency department, King Fahd Medical City, e-mail: wafa.alaswad1@gmail.com, email: amal.alqufly@gmail.com (Corresponding author: Wafa Ali)

Ibrahim Aljabr is with Unaizah College of Medicine, Qassim University, email: Ibrahimaljabr1241@gmail.com
2020 [4]. The first case of this new strain in Saudi Arabia appeared on 2 March 2020 in a traveller returning from Iran. As of 12 May 2021, Saudi Arabia has reported 428369 cases, with 7098 deaths [5].

With the ongoing global crisis, several control measures have been postulated to slow the spread of infection; these include social distancing, partial and comprehensive lockdowns, closure of schools and businesses, and/or the wearing of face masks in public, in addition to the recent vaccination campaigns. Such measures may have flattened the epidemic curve, but the resurgence of cases continues. The persistence of this pandemic highlights the need for more in-depth analysis of the determinants of disease transmissibility and the perception and attitude toward the abovementioned preventive measures, which was the purpose of this study.

In continuity with our previous work [6] exploring COVID19 in different Saudi Arabian provinces, here we aim to study the virus in Al Qassim - the fifth most densely-populated province, with 215858 inhabitants [7].

This study aims to investigate the prevalence of infection in different cities and villages in $\mathrm{Al}$ Qassim. We also aim to explore the sociodemographic factors that influence disease transmission, and the number of participants who received zinc and/or azithromycin. Finally, we aim to explore perceptions toward vaccination and social isolation.

\section{METHODS}

This is a cross-sectional study conducted in Al Qassim province in March 2021. The inclusion criteria were adults of both genders, older than 18 years, living in Al Qassim province. The data were collected via a structured questionnaire in Arabic, using an online survey tool, and the survey was distributed via social media. The authors developed the self-reported questionnaire, which consists of demographic questions, questions about infection and exposure to infected individuals, and inquiry into levels of awareness and practice regarding self-isolation, zinc supplements, azithromycin and vaccination. We included a photograph of the azithromycin drug package for ease of identification, and the brand names of the medications available in the province. We calculated a sample size of 385 using the online Raosoft ${ }^{\circledR}$ calculator (with a significance level of 0.05 , a $5 \%$ margin of error and $95 \%$ confidence level) and expected a response distribution of $50 \%$.

We also collected data reported by the Weqaya, Saudi Centre for Disease Prevention and Control from the start of the pandemic until 9 May 2021. 


\section{RESULTS}

Until 9 May 2021, the province had 15497 positive COVID19 cases, comprising a prevalence of $1.46 \%$, as illustrated in Table 1.

Demographics: The total number of participants in ourstudy was 511; their demographics are illustrated in Table 2. The majority were younger than 40 years and did not have chronic diseases.

Prevalence of COVID-19 infection and admission rate: The number of participants who acquired the infection was $34.8 \%$ $(\mathrm{n}=178)$, and the admission rate was $1.6 \%(\mathrm{n}=8)$. In all of the cases, the reported reason for admission was related to the need for oxygen supplementation.

Prevalence of exposure: The exposure rate to a positive or probable case was $52.1 \%(\mathrm{n}=266)$.

Predictors for exposure: The exposure rate did not differ with respect to marital status, gender, age, educational level, or presence of chronic diseases; $\mathrm{p}>0.05$.

Predictors for self-isolation: Self-isolation was more noticeable among younger age groups, as illustrated in Table 3, while single participants were more likely than married participants to self-isolate: $58.9 \%(\mathrm{n}=129)$ compared with $46.9 \%(\mathrm{n}=137)$; $X^{2}(1)=7.20, p<0.05$. Nonetheless, self-isolation did not reveal a gender predominance and was not influenced by educational level or the presence of chronic diseases; $p>0.05$.

Zinc supplementation and azithromycin use: 70 participants were prescribed zinc, comprising $39.3 \%$ of those who acquired the infection; however, data were missing for 151 participants. Meanwhile, 17.97\% ( $\mathrm{n}=32)$ reported using azithromycin during their illness. Of age, gender, educational level, marital status and presence of chronic diseases, no significant predictor was detected for the prescription of zinc or azithromycin; $\mathrm{p}>0.05$.

Social distancing and isolation instructions: The majority of participants reported that the community 'sometimes' complied with social distancing and isolation instructions, $63 \%$ $(\mathrm{n}=322)$, while $26.8 \%(\mathrm{n}=137)$ affirmed community adherence with such measures and $10.2 \%(\mathrm{n}=52)$ believed that the community did not adhere.

Perceptions of community compliance with social distancing measures did not differ between those who acquired the infection and those who did not; $p>0.05$; there was also no difference noted among different age groups; $\mathrm{p}>0.05$. However, a significant statistical difference was noted between males and females in their perception of compliance with social distancing and isolation instructions; $\mathrm{X}^{2}(2)=10.69$, $\mathrm{p}<0.05$. Females reported a $21.5 \%(\mathrm{n}=63)$ compliance rate, $11.9 \%(\mathrm{n}=35)$ noncompliance, and $66.6 \%(\mathrm{n}=195)$ reported that compliance 'sometimes' occurs. Males, on the other hand, reported a $33.9 \%(\mathrm{n}=74)$ compliance rate, $7.8 \%(\mathrm{n}=17)$ noncompliance, and $58.3 \%(\mathrm{n}=127)$ that compliance 'sometimes' occurs. Marital status had no influence on the perception of compliance; $\mathrm{p}>0.05$.

Vaccination: The majority of participants $-79.5 \%(n=406)$ - were not vaccinated However, $77.9 \%(n=398)$ perceived the vaccine to be effective in preventing virus dissemination. In line with that number, $72.6 \%(\mathrm{n}=371)$ reported their willingness to receive the vaccine whenever possible.
There was no statistically significant difference in age between those who planned to take the vaccine and those who did not, $\mathrm{p}>0.05$; similarly, no specific gender, marital status or educational level was a predictor of such plan; $p>0.05$. Likewise, perception of the vaccine's effectiveness did not differ among age groups or marital status, and was not influenced by educational level; $\mathrm{p}>0.05$.

Patients with chronic diseases did not differ from medically free patients in their plan to receive the vaccine; $p>0.05$. This was also noted with regard to planning to take the vaccine and perception of disease prevention by vaccination; $p>0.05$. Similarly, previously-infected participants did not differ from the others with respect to their intention to take the vaccine or their perception of the vaccine's effectiveness; $p>0.05$.

\section{DISCUSSION}

This article is part of series investigating the sociodemographic determinates of COVID-19 infection in different provinces in Saudi Arabia. The infection rate in Al Qassim province was $1.46 \%$, which is higher than in Riyadh province (1.24\%) and Makkah Al-Mukarramah province (1.21\%) [5],

[8] , [9], but lower than in Eastern province (2.4\%) [10]. Uyun Al-Jiwa and Riyadh Al-Khabra revealed the highestprevalence of infection compared with other areas in the province, with a rate of $3.42 \%$ and $3.13 \%$ respectively. Although lower than the aforementioned two regions, Al Mithnab also had a high prevalence of infection, at $2.42 \%$. Specific surveillance measures should target those regions in particular.

The admission for the province was $1.6 \%$, in line with that of Jizan province [6] and lower than Riyadh City's admission rate of $4.5 \%$ [11].

Half of the participants in our sample were exposed to a positive or probable case. The lack of predictors for such exposure is concerning, as it cannot be determined who is at risk; hence, health advocates should target the community with a holistic approach. Older individuals were less likely to self-isolate than the younger age groups after contact with probable or positive cases; while participants with chronic diseases were no more or less likely to self-isolate than those who were medically free. The older age groups and those with chronic diseases are two cohorts at risk for disease severity and mortality [12], [13], [14] and thus, we believe, should be the target for health advocacy in the coming public health campaign.

Self-isolation at home reduced community transmission by $30 \%$ [15]. Nonetheless, this analysis uncovered that married participants were less likely to self-isolate after exposure to probable or confirmed cases. This is an essential determinant of infection transmissibility, particularly when other members of the household work away from the home. Such an attitude was also noted in Jizan province, and explained the high infection rate within this cohort [6].

Azithromycin is not routinely recommended for treatment of COVID-19 patients [16], [17]. Its use should be limited to those individuals requiring invasive machinal ventilation; even then, it remains controversial [18]. Our study revealed approximately $18 \%$ who were discharged with azithromycin; 
TABLE I

THE NUMBER OF CASES AND RECOVERIES IN DIFFERENT CITIES/VILLAGES OF AL QASSIM PROVINCE

\begin{tabular}{lllll}
\hline City/village & Total population (n) & Positive cases (n) & Recovered (n) & Prevalence (\%) \\
Unayzah & 163729 & 2745 & 2661 & 1.68 \\
Buraydah & 590312 & 6152 & 5925 & 1.04 \\
Ar Rass & 109551 & 1160 & 1097 & 1.06 \\
Al Mithnab & 44043 & 1064 & 1046 & 2.42 \\
Al Bukairiyah & 57621 & 676 & 657 & 1.17 \\
Uglat Asugour & 20675 & 104 & 97 & 0.50 \\
Al Badayea & 57164 & 674 & 652 & 1.18 \\
Al Assiyah & 39763 & 749 & 715 & 1.88 \\
Riyadh Al-Khabra & 24975 & 781 & 746 & 3.13 \\
An Nabhaniyah & 46429 & 262 & 256 & 0.56 \\
Dariyah & 24447 & 223 & 221 & 0.91 \\
Ash Shimasiyah & 10605 & - & - & - \\
Uyun Al-Jiwa & 26544 & 907 & 864 & 3.42 \\
Total & 1215858 & 15497 & 14937 & 1.46 (Mean) \\
\hline
\end{tabular}

TABLE II

2. PARTICIPANTS' DEMOGRAPHICS

\begin{tabular}{ll}
\hline VARIABLES & PERCENTAGES \% (N) \\
Age group & \\
Younger than 18 years & $4.7(24)$ \\
18-30 years & $40.5(206)$ \\
30-40 years & $16.3(83)$ \\
40-50 years & $23.8(121)$ \\
Older than 50 years & $14.7(75)$ \\
Gender & \\
Female & $57.3(293)$ \\
Male & $42.7(218)$ \\
Marital status & \\
Single & $42.7(219)$ \\
Married & $57.1(292)$ \\
Educational LEVEL & \\
Less than high school & $4.1(21)$ \\
High school & $14.5(74)$ \\
Diploma & $15.1(77)$ \\
Bachelor's degree & $59.7(305)$ \\
Masters and above & $6.7(34)$ \\
Chronic diseaseS & $15.9(81)$ \\
Yes & $84.1(430)$ \\
No &
\end{tabular}

TABLE III

3. SElf-isolation AMONG DifFERENT AGE GROUPS

\begin{tabular}{lll}
\hline Age group & Self-isolation Percentage \% (n) & Statistical test \\
Younger than 18 years & $79.2(19)$ & Linear-by- \\
$18-30$ & $56.3(116)$ & linear \\
$30-40$ & $51.8(43)$ & association \\
$40-50$ & $48.8(59)$ & $(1)=13.7$, \\
Older than 50 years & $36.0(27)$ & $\mathrm{p}<0.05$ \\
\hline
\end{tabular}

such practice requires a protocolised clinical guideline to ensure cost-effective practice and to mitigate any future surge in resistance.

Zinc supplementation is believed to have antiviral properties and to enhance immunity, especially among elderly and immunocompromised individuals [19]. In our study, a significant number did not answer the question about whether or not they had used it; hence, more data are needed to ascertain whether this practice should be emphasised.

In the broader community, social distancing is designed to reduce interactions between people, especially those who are infected by asymptomatic. Consistent with a previous local report [20], our study revealed that one third of the community practise strict adherence to social distancing and self-isolation, although the majority reported that there was 'sometimes' compliance with such measures, which might reflect a change in the community's collective perception of the disease and its transmission. A subgroup analysis revealed that males' perception of community compliance is higher than that of females; this hints at a lower level of compliance in the narrower female community; e.g. shopping malls and/or family and neighbourhood gatherings. Females should therefore be the target segment for social distancing compliance during this period.

Vaccines have long been an essential factor in improving health outcomes and life expectancy and, despite controversy, vaccination is possibly the final step in controlling this pandemic. Nevertheless, for a vaccination programme to be 
successful, a high rate of acceptance must be ensured. Data from a national survey showed an acceptance rate of around $65 \%$ before the vaccines was released [21]. In our sample, perception of the vaccine's effectiveness and the acceptance rate were approximately $75 \%$. It is reassuring to note that such acceptance was not influenced by age, gender, educational level, or the presence or lack of chronic diseases. As such, we see no need to allocate resources to target the elderly or those with chronic diseases through a vaccination promotion campaign.

\section{CONCLUSION}

The current study's findings emphasise the need to adopt further measures to encourage and educate the public about the importance of adherence to precautionary measures such as social distancing and limiting social gatherings as a strategy to control and limit the spread of this pandemic.

Our study has two limitations; firstly, it is cross-sectional, depicting community response at a single point in time. Furthermore, generalisation of these results is hindered by the use of social media for enrolment; this targets smartphone users while leaving the views of other community segments - mainly poor and older people vulnerable to COVID-19 unexplored.

\section{REFERENCES}

[1] Cascella M, Rajnik M, Aleem A, Dulebohn SC, Di Napoli R, Features, Evaluation, and Treatment of Coronavirus (COVID-19), 2021 April 20. In: StatPearls [Internet]. Treasure Island (FL): StatPearls Publishing; 2021 Jan. PMID: 32150360.

[2] World Health Organization. Geneva (Switzerland): World Health Organization; 2003, Summary of probable SARS cases with onset of illness from November 12002 to July 31 2003, [Internet] Dec [cited 2020 April 1]. Available from: https:/www.who.int/csr/sars/country/table2004 04 21/en/

[3] World Health Organization, Middle East Respiratory Syndrome Coronavirus (MERS-CoV) - The Kingdom of Saudi Arabia, 2019, WHO. Available from https://www.who.int/csr/don/18-december-2019-mers-saudiarabia/en/

[4] Zhu N, Zhang D, Wang W, Li X, Yang B, Song J, Zhao X, Huang B, Shi W, Lu R, Niu P, Zhan F, Ma X, Wang D, Xu W, Wu G, Gao GF, Tan W; China Novel Coronavirus Investigating and Research Team, $A$ Novel Coronavirus from Patients with Pneumonia in China, 2019, N Engl J Med. 2020 February 20; 382(8):727-733. doi: 10.1056/NEJMoa2001017. Epub 2020 January 24. PMID: 31978945; PMCID: PMC7092803.

[5] Ministry of Health, Corona-V. corona-v. 2021 accessed from https://corona-v.com/

[6] Sahli, S, and S. Bin Nafisah, The Prevalence of COVID-19 in Jizan Region, Saudi Arabia: A Demographic Analysis, The Journal of Medicine, Law \& Public Health, vol. 1, no. 2, Apr. 2021, pp. 15-18, https://www.jmlph.net/index.php/jmlph/article/view/4

[7] The Sixteenth Services Guide 2017 Al-Qaseem Region [Internet], 2017 [cited 2021 May 11]. Available from: https://www.stats.gov.sa/sites/default/files/al-qaseem_region_en.pdf

[8] Population in Riyadh egion by gender, age group and nationality (Saudi/Non-Saudi), General Authority for Statistics [Internet], [cited 2021 May 11], available from: https://www.stats.gov.sa/en/5721

[9] Population in Makkah region by gender, age group and nationality (Saudi/Non-Saudi) - mid-2016 A.D, General Authority for Statistics [Internet], [cited 2021 May 11], available from: https://www.stats.gov.sa/en/5308

[10] The Sixteenth Services Guide 2017 Eastern Region [Internet], 2017 [cited 2021 May 11], available from: https://www.stats.gov.sa/sites/default/files/eastern region en.pdf

[11] Al-Omari A, Alhuqbani WN, Zaidi ARZ, Al-Subaie MF, AlHindi AM, Abogosh AK, Alrasheed AK, Alsharafi AA, Alhuqbani MN, Salih S, Alhedaithy MA, Abdulqawi R, Ismail AF, Alhumaid S, Hamdan N, Saad F, Olhaye FA, Eltahir TA, Alomari M, Alshehery M, Yassiri A, Al-Tawfiq JA,
Al Mutair A, Clinical characteristics of non-intensive care unit COVID-19 patients in Saudi Arabia: A descriptive cross-sectional study, J Infect Public Health. 2020 Nov; 13(11):1639-1644. doi: 10.1016/j.jiph.2020.09.003. Epub 2020 September 21. PMID: 33004305; PMCID: PMC7505603.

[12] Matta S, Chopra KK, Arora VK, Morbidity and mortality trends of Covid 19 in top 10 countries, Indian J Tuberc. 2020 Dec; 67(4S):S167-S172. doi: 10.1016/j.ijtb.2020.09.031. Epub 2020 October 8. PMID: 33308665; PMCID: PMC7543896.

[13] Liu H, Chen S, Liu M, Nie H, Lu H, Comorbid Chronic Diseases are Strongly Correlated with Disease Severity among COVID-19 Patients: A Systematic Review and Meta-Analysis, Aging Dis. 2020 May 9; 11(3):668-678. doi: 10.14336/AD.2020.0502. PMID: 32489711; PMCID: PMC7220287.

[14] Kang SJ, Jung SI, Age-Related Morbidity and Mortality among Patients with COVID-19, Infect Chemother. 2020 Jun; 52(2):154-164. doi: 10.3947/ic.2020.52.2.154. Epub 2020 June 12. PMID: 32537961; PMCID: PMC7335648.

[15] Kucharski AJ, Klepac P, Conlan AJK, Kissler SM, Tang ML, Fry H, et al, Effectiveness of isolation, testing, contact tracing, and physical distancing on reducing transmission of SARS-CoV-2 in different settings: a mathematical modelling study, The Lancet Infectious Diseases. 2020; 20(10):1151-60.

[16] PRINCIPLE Trial Collaborative Group, Azithromycin for community treatment of suspected COVID-19 in people at increased risk of an adverse clinical course in the UK (PRINCIPLE): a randomised, controlled, open-label, adaptive platform trial, Lancet. 2021 Mar 20; 397(10279):1063-1074. doi: 10.1016/S0140-6736(21)00461-X. Epub 2021 March 4. PMID: 33676597; PMCID: PMC7972318.

[17] Lansbury L, Lim B, Baskaran V, Lim WS, Co-infections in people with COVID-19: a systematic review and meta-analysis, J Infect. 2020 Aug; 81(2):266-275. doi: 10.1016/j.jinf.2020.05.046. Epub 2020 May 27. PMID: 32473235; PMCID: PMC7255350.

[18] RECOVERY Collaborative Group, Azithromycin in patients admitted to hospital with COVID-19 (RECOVERY): a randomised, controlled, openlabel, platform trial, Lancet. 2021; 397(10274), 605-612. https://doi.org/10.1016/S0140-6736(21)00149-5.

[19] Samad N, Sodunke TE, Abubakar AR, Jahan I, Sharma P, Islam S, Dutta S, Haque M, The Implications of Zinc Therapy in Combating the COVID-19 Global Pandemic, J Inflamm Res. 2021 February 26; 14:527-550. doi: 10.2147/JIR.S295377. PMID: 33679136; PMCID: PMC7930604.

[20] Aldarhami A, Bazaid AS, Althomali OW, Binsaleh NK, Public Perceptions and Commitment to Social Distancing 'Staying-at-Home' During COVID-19 Pandemic: A National Survey in Saudi Arabia, Int J Gen Med. 2020 September 22; 13:677-686. doi: 10.2147/IJGM.S269716. PMID: 33061535; PMCID: PMC7519831.

[21] Al-Mohaithef M, Padhi BK, Determinants of COVID-19 Vaccine Acceptance in Saudi Arabia: A Web-Based National Survey, J Multidiscip Healthc. 2020 Nov 20; 13:1657-1663. doi: 10.2147/JMDH.S276771. PMID: 33262600; PMCID: PMC7686470. 